\title{
Creating an Infrastructure Education Community of Practice
}

\author{
Dr. Philip J. Parker P.E., University of Wisconsin, Platteville \\ Dr. Carol Haden, Magnolia Consulting, LLC
}

Carol Haden is s Senior Evaluator with Magnolia Consulting, LLC. She holds a doctorate in Curriculum and Instruction with an emphasis on program evaluation from Northern Arizona University. Dr. Haden has extensive experience in the evaluation of formal STEM education projects across the K-20 spectrum and the evaluation of informal STEM Education and Public Outreach (E/PO) programs. She has designed and implemented evaluations of programs funded by the National Science Foundation, the William and Flora Hewlett Foundation, the Arizona Board of Regents, Goddard Space Flight Center, Jet Propulsion Laboratory and the Arizona Department of Education, among others. She has a special interest in supporting exemplary and equitable science education for traditionally underserved populations.

\section{Dr. Steven D Hart, U.S. Military Academy}

LTC Steve Hart is currently assigned as the ERDC Engineering Fellow and Director of Infrastructure Studies at West Point. He has taught numerous civil engineering courses including innovative courses on Infrastructure Engineering and Critical Infrastructure Protection and has authored numerous articles and a book chapter on these subjects. He is the developer and lead proponent of The Critical Infrastructure Symposium, now in its fifth year. He is active in The Infrastructure Security Partnership and the American Society of Civil Engineers including services on the Committee on Critical Infrastructure as well as the American Society of Engineering Education.

\section{Dr. Michael Keith Thompson, University of Wisconsin, Platteville}

Dr. M. Keith Thompson is currently an associate professor at the University of Wisconsin - Platteville in the Department of Civil \& Environmental Engineering. He earned his BS degree in Civil Engineering from North Carolina State University and his MS and PhD degrees in Civil Engineering from the University of Texas at Austin. His technical speciality is structural engineering with a focus on structural concrete. He has taught a variety of structural engineering courses, freshman level introduction to engineering courses, and infrastructure education courses. His research interests include curriculum reform, enhanced teaching and advising practices, improving retention of undergraduate students, and using learning analytics to improve institutional practice.

\section{Dr. Matthew W Roberts, University of Wisconsin, Platteville}

Matthew Roberts has been teaching at UW-Platteville since 2002. He is originally from Denver, Colorado and attended Brigham Young University for his B.S. in Civil Engineering. He then spent four years as a civil engineering officer in the U.S. Air Force. After his military service, he completed graduate work at Texas A\&M University. He teaches classes on reinforced concrete design, structural steel design, and other structural engineering topics. 


\section{Creating an Infrastructure Education Community of Practice}

The University of Wisconsin-Platteville civil engineering and environmental engineering programs and the civil engineering program at the United States Military Academy have successfully transformed their curricula in the last five years. Both universities have developed, piloted, and institutionalized two new infrastructure-themed courses. As a result of our independent (to date) efforts, we have generated a wide variety of teaching materials for the four courses. Importantly, the transformation of our curricula has involved more than adding new courses; as a result of having all department faculty involved in the planning and implementation, our institutions have experienced a "trickle down" effect, in which new infrastructure-themed material has been added to nearly every course and entire course sequences have been modified. As a result, important topics such as resilience, infrastructure protection, environmental impacts, and sustainability are presented to students in a variety of courses within the context of infrastructure.

Over the next year, the two universities will share their experiences and expertise with six collaborating institutions. Rather than simply "handing off" the materials to the collaborating institutions, the universities intend to build a community of practice $(\mathrm{CoP})$. A CoP is a "group of people who share a concern or a passion for something they do and learn how to do it better as they interact regularly" (Wenger, 2006). As such, there are three aspects to this definition reflected in our CoP:

- We have collected a group of faculty who share a passion for infrastructure education and share a need to create a new course for their curriculum.

- CoP members will continuously improve the content and delivery of the course by sharing updates and improvements to each lecture topic.

- Regular interactions will take place via a workshop in the summer of 2014, regular preworkshop internet meetings, regular post-workshop internet meetings, and visits to the collaborating institutions by the PIs.

Thus, the CoP will provide two-way conversation between the creators of the material and the initial adopters at the partner universities, with the intent that eventually the line between these two groups is blurred.

This paper and its companion poster are the result of a very recent (September 1,2013) funding award from NSF (TUES Type 2; "Collaborative Research: Training Next Generation Faculty and Students to Address the Infrastructure Crisis"; award number 1323279). The outcomes of the proposed work are:

- Establish and sustain the Center for Infrastructure Transformation and Education (CIT-E) as the source for infrastructure education materials that are continuously improved by a vibrant community of practice 
- Develop educational expertise in infrastructure topics and in pedagogy in faculty at six collaborating institutions

- Deliver, assess, and institutionalize infrastructure-themed courses or modules for Civil and Environmental Engineering (CEE) majors and other majors at collaborating institutions

- Enhance the ability of CEE students to view components and systems designed in CEE subdisciplines as integral parts of a larger system (i.e. the infrastructure)

- Enhance the ability of CEE students to view infrastructure challenges from a societal perspective, rather than solely from a technical perspective

This paper presents the progress to date, which includes: 1) holding pre-workshop meetings with all collaborators; 2) preparation of the course materials for dissemination to other users; 3 ) preliminary assessment of the effectiveness of the pre-workshop meetings

1. Pre-workshop meetings

Three pre-workshop meetings have been held using an online meeting tool, Blackboard Collaborate. The first two meetings were focused on administrative aspects of the grant while the third meeting was a presentation on the ASCE Body of Knowledge. As such, the meetings have:

- Allowed members to "meet" each other by presenting an autobiographical slide

- Ensured that all members can provide input on the project's logic model and the objectives of the 2014 workshop.

- Allowed members to become comfortable in communicating in an online environment.

While conducting these meetings, the PIs have focused on making the meetings as "active" as possible using the following methods:

- Think-Pair-Share - The "Think-Pair-Share" method is a common active learning exercise, in which students think of a response to a question; after a brief (1-2 minutes) period, students pair up with each other to discuss their responses; the final step is to share their findings with the entire class. In order to save time, the "pair" step was omitted in the pre-workshop meetings and participants wrote their responses on a community whiteboard following a 1-minute long "thinking" time.

- Hand-raising - Blackboard Collaborate allows participants to raise their hand when they want to ask a question. We imposed a rule that all participants must use this feature to prevent them from speaking over one another.

- Polls - the online meeting environment allows participants to respond to polls. We have used polls as well as asking yes/no questions and simply asking participants to 
respond with a "thumbs up" or "thumbs down" icon to quickly measure participant opinions.

- "Name-calling" - As promoted in various teaching workshops such as ASCE Excellence in Civil Engineering Education Teaching (ExCEEd) (Estes, et al, 2005), we believe in calling on participants by name to make the online interaction more like a face-to-face meeting. For example, we call on participants by name if they have not responded to a poll question or have not spoken up in the past 15 minutes.

- Group breakouts - Blackboard Collaborate allows groups of participants to break away from the main group. This allows for small groups to form, which makes discussion between members less intimidating than does speaking up to a large group. Each group writes on its own whiteboard, and these whiteboards are shared once the breakout session is ended by the moderator.

As a result of our experience in these pre-workshop meetings, we have formulated the following list of "best practices" for moderating online meetings.

- Incorporate active learning activities as detailed above.

- Place the online meetings on collaborators' calendars (e.g. Microsoft Outlook or Google Calendar) such that the meetings are part of the collaborators' schedules, just like "real" meetings

- Provide all participants with an agenda at least 48 hours in advance

- Ensure that the meetings have measurable objectives

- Prepare extensively for the online meeting to ensure that it runs smoothly

- Request participants to log into the meeting five minutes early to iron out any technology issues

- Start meetings on time

- Keep meetings under 45 minutes

- Request that speakers raise their hand and announce their name before speaking

- Before the meeting starts, rather than have everyone staring at a blank screen (or having their attention diverted to e-mail or other tasks), try one of the following:

- Post a slide with a main topic for the day's meeting (e.g. a slide of the logic model)

- Share a brain teaser

○ Provide a "question of the day"

- When sharing PowerPoint shows, keep the slides very simple (i.e. avoid animations) so that transitions are not delayed for those with slow internet connections

We are also in the process of implementing other steps to help ensure the success of the virtual CoP. For example, we intend to administer a "pre-knowledge probe" to find out exactly what our participants know about various topics related to our CoP (e.g. knowledge of various portions of the infrastructure, of pedagogical tools, etc.). As such, when we identify participants' 
expertise area, we intend to take advantage of that expertise by making them leaders and future moderators on those topics. We are also continuing to understand the importance of responding to requests from community members as soon as possible and making sure people know where to go online to find shared materials.

2) Preparation of the course materials for dissemination

The CoP will be sharing materials for two existing courses, one created and delivered at University of Wisconsin-Platteville and one at United States Military Academy. For each lecture for each course, a folder has been created that includes notes, companion PowerPoint file, board notes, background reading, and assignments. All materials are housed on Box.com. This site allows users to leave comments for each file; one of the goals of the project is that users will leave comments after using a file (e.g. an assignment or a PowerPoint file) that will further enhance the content.

3) Preliminary assessment of pre-workshop meetings

At the conclusion of each meeting, participants are provided with a link to an on-line survey. Results for the first and third pre-workshop meeting are provided in Figure 1 and Figure 2. The results show that the respondents are overall quite favorable in the organization and utility of the meetings. The results of the second meeting showed less satisfaction in some areas; this may due to the fact that the organizers did not effectively communicate the purpose of the second meeting until near the end of the meeting. Some of the less favorable results, along with written comments, both positive and negative, have been taken into account in the ongoing formulation of $\mathrm{CoP}$ best practices. 


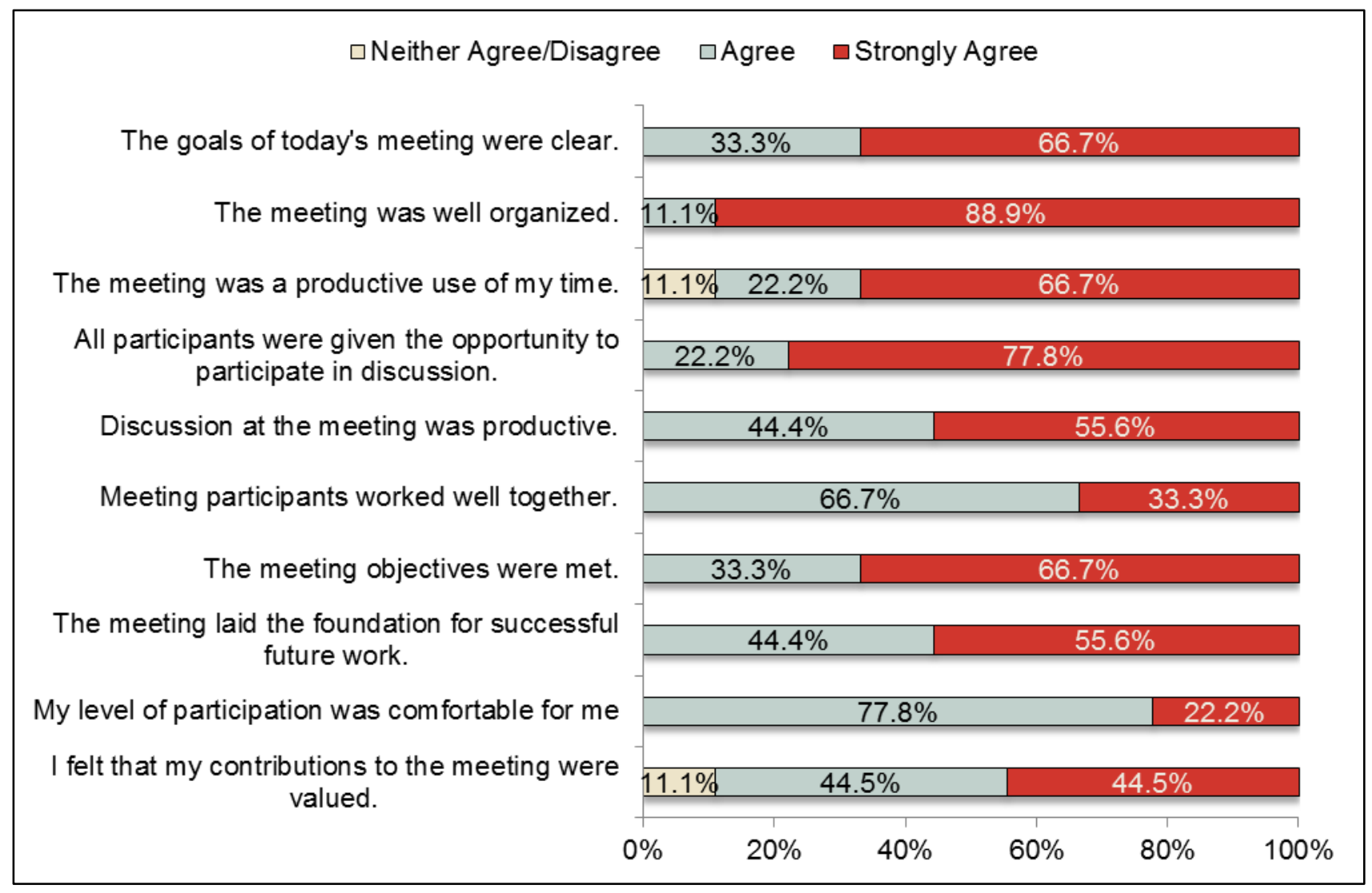

Figure 1: Assessment results from first pre-workshop meeting

Acknowledgment: The authors gratefully acknowledge the support of the National Science Foundation Division of Undergraduate Research (Collaborative Research: Training Next Generation Faculty and Students to Address the Infrastructure Crisis; Award Number 1323279). 


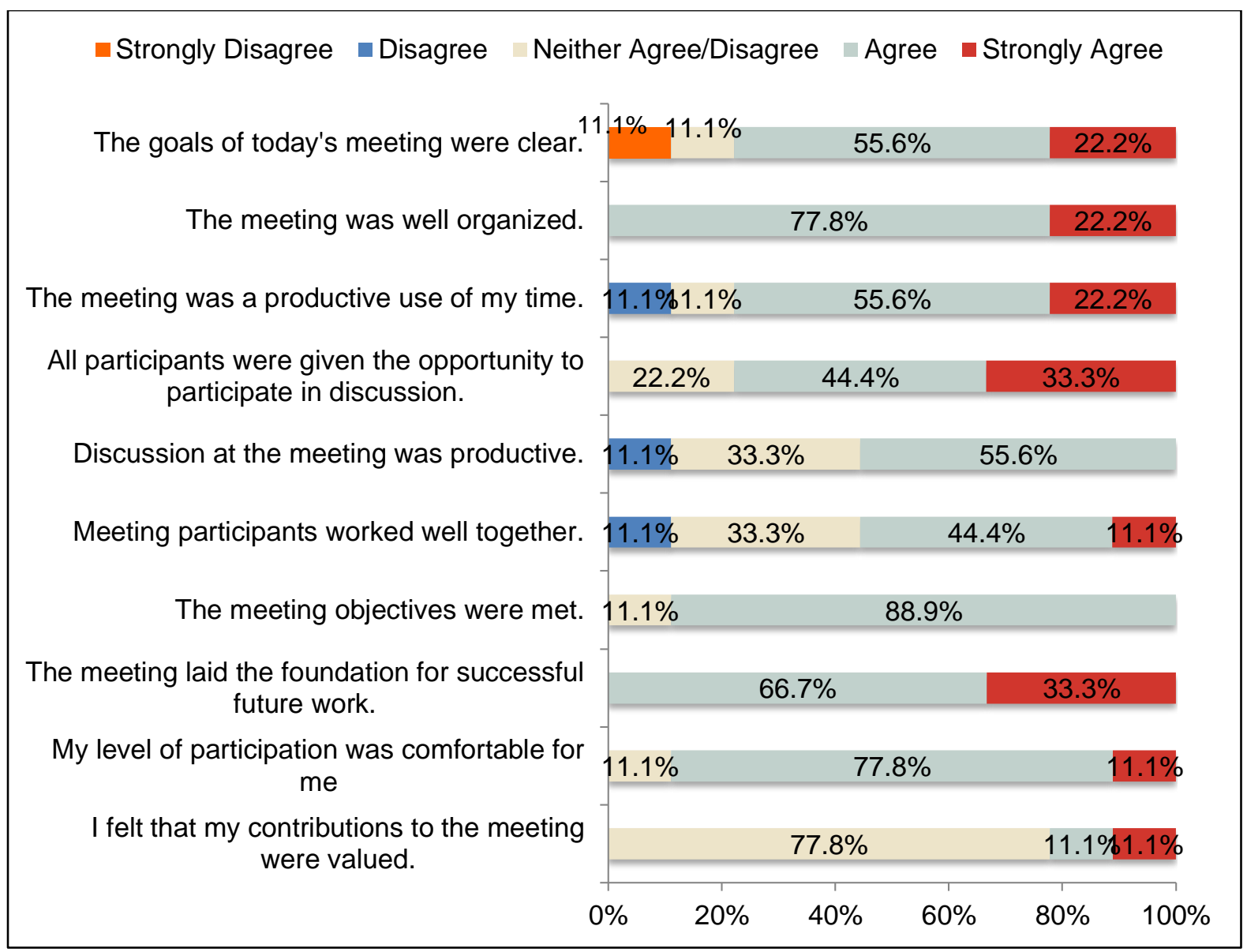

Figure 2: Assessment results from third pre-workshop meeting (presentation on ASCE Body of Knowledge)

Reference cited

Wenger, E. “Communities of practice: A brief introduction.” June, 2006. Accessed from http://wenger-trayner.com/theory/ on October 10, 2013

Estes, A., Welch, R., and Ressler, S. (2005). "The ExCEEd Teaching Model.” J. Prof. Issues Eng. Educ. Pract., 131(4), 218-222. 